guards against the entrance of air into bioodvessels, for he knows that death would inevitably follow the entrance of even a relatively small quantity of air into the veins.

Harvey also upset the doctrine that the blood passes from the right to the left ventricle through pores in the septum of the heart. He says "no such pores can be demonstrated" (lib. cit., p. 17), and "why have recourse to invisible porosities" "..... "when there is so open a vay" from the right to the left side of the heart through the pulmonary artery and pulmonary veins. But he also adduces experiments. He says (lib. cit., p. 135) that if you tie the pulmonary veins in a living animal, and so prevent the blood from entering the leit side of the heart, death ensues; and he gives you to understand that the results are similar to those in death from asphyxia-the right side of the heart becoming engorged, the left side comparatively empty ; and then he concludes that "as all these particulars have been recognised by the senses, it is manifest that the blood passes through the lungs and not through the septum" in its course from the right to the left side of the heart, and that the right ventricle is intended to drive the blood through the bloodvessels of the lungs, and through them alone.

There was another great fact overlooked by all the predecessors of Harvey which was of fundamental importance in leading him to the idea that the blood moves in a circle. He evidently asked himself the question, How much blood does the heart transmit from the vena cava to the arteries in a given time? He found that in the dead body the left ventricle holds upwards of two ounces of blood. Then he says (lib. cit., p. 48), let us assume how much less the heart will hold when contracted than it does when dilated, and how much blood it projects into the aorta at each contraction. "Let us suppose that, as approaching the truth, the fourth or fifth, or sixth, or even but the eighth part of its charge, is thrown into the artery at each contraction. This would give either half an ounce, or three drachms, or one drachm, of blood as propelled by the heart at each pulse into the aorta, which quantity, by reason of the valves at the root of that vessel, can by no means return into the ventricle. Now, in the course of half an hour, the heart will have made more than one thousand beats, in some as many as two, three, and even four thousand. Multiplying the number of drachms propelled by the number of pulses, we shall have either one thousand half-ounces or one thousand times three drachms, or a like proportional quantity of blood, according to the amount which we assume as propelled with each stroke of the heart, sent from this organ into the artery -a larger quantity in every case than is contained in the whole body $!$...... But let it be said that this does not take place in half an hour, but in an hour, or even in a day; any way, it is still manifest that more blood passes through the heart" [in that time] "than can either be supplied by the whole of the food consumed or than can be contained in the veins at the same moment. In short, it could be furnished in no other way than by making a circuit and returning." And then he says : "This truth indeed presents itself obviously before us when we consider what happens in the dissection of a living animal. The great artery need not be divided, but only a small branch, to get the whole blood in the body, that of the veins as well as that of the arteries, drained away in the course of half an hour or so" (lib. cit., p. 50). Observe how he proved by that experiment that all the blood of the veins flows through the heart into the arteries, and can escape by an opening made into one of them, even one of small size. These are the facts that led Harvey to believe that the blood moves in a circle, and it is to be observed that he nowhere mentions the valves of the veins as in any way assisting him towards his great conception.

(To be concluded.)

ThE INSANE IN WORKhoUses. - The number of lunatics, idiots, and persons of unsound mind, detained in workhouses in England and Wales, on Jan. 1st, 1881, was 16,811 - an increase of 347 on the number so detained on the corresponding day of the previous year. Of this number, however, 4718 were inmates of the Metropolitan District Asylums at Leavesden, Caterham, and Darenth, which are in the legal position of workhouses within the meaning of the Lunacy Acts; so that 12,093 lunatics or weak-minded persons were detained in workhouses proper.

\section{NOTE ON THE CURABILITY OF TABES DORSALIS.}

\author{
BY E. LONG FOX, M.D.
}

IN the present state of medical knowledge the words "always" and "never" should seldom be used. So many things are possible; so many exceptional cases occur in all departments of medicine; so rapid is the progress of the differentiation of disease, that what is accepted as true to-day may to-morrow admit of a different interpretation. What is cure? It is the cessation of all morbid phenomena, plus the return to a normal condition of the organ or organs affected. In many cases we conclude that the latter has occurred because the morbid symptoms have vanished. But in certain affections of the nervous system this connexion between relief of symptoms and cure of lesion does not hold good. This is the case in some states of the brain. It is notably so of the spinal cord.

Dr. Friedrich Schultze (Arch. fïr Psychiatrie, Band 12) has lately recorded a case that bears on this point. In brief it was as follows: A man, aged forty-three, previously healthy, came under observation in April, 1871, but had suffered lancinating pains in the lower limbs for two or three years. For one year there had been unsteadiness of gait, commencing vesical phenomena, and feeling of numbness in the left ulnar nerve. These symptoms increased more and more. Unsteadiness of gait, especially in the dark, was worse. There was nocturnal enuresis, and by day it was difficult for him to retain his urine. Under the use of nitrate of silver his condition had been better of late; he did not sway so much when the eyes were closed, and the irregular movements of the legs were almost gone. He was placed under galvanic treatment. In a fortnight there was improvement of gait, and hardly any sensory abnormality, except numbness of the left ulnar in the fourth and fifth fingers, diminution of sexual desire, nocturnal enuresis. By the middle of May the enuresis had vanished. He could go up a mountain without great fatigue; the lightning pains quite gone. Vesical weakness present, but slight. Left ulnar numbness persisted.-February, 1872: Improvement continues; no pains ; much less ulnar numbness. Feeling of fatigue in lower extremities still abnormally great; fatigue even after one hour's walk. Galvanic treatment resumed. In 1873 no pains; hardly a trace of ulnar numbness. No ataxic gait. Occasional nocturnal enuresis and dropping of urine. So to the end of June, 1880, about twelve years from the beginning of the phenomena. At this time gait was normal. No ptosis; no sensory abnormalities. Complete loss of patellar tendon-reflex on both sides; slight vesical paralysis, with nocturnal enuresis and dripping of urine by day ; catarrh of bladder ; urine not alkaline. Pupils act weakly to light. The galvanism had no effect on the bladder symptoms. No spinal fatigue after an hour's walk. The patient died suddenly from accidentally swallowing some corrosive substance.

Post-mortem examination.-Spinal cord abnormally thin and pale; spinal dura mater and pia mater normal; anterior portion of cerebral pia mater thickened; no granulation of ependyma. After preparation of spinal cord the volume of the cord small in dorsal and lumbar regions; less so in cervical ; great degeneration of posterior columns, only the sections bordering on the posterior commissure were rich in nerves. In the middle part of the lumbar bulb the parts of the posterior columns lying directly on the posterior horns were somewhat rich in nerves. In the dorsal region nerve fibres were found in the parts bordering the anterior third of the posterior horns. In the cervical region Goll's columns were free, but the border between the fasciculi graciles and the fasciculi cuneati was marked by a small zone of degeneration. In the upper two thirds of the cerrical bulb there was a complete triangle of degeneration, the base of which lay on the cuneiform columns of the periphery, and the apex in the small zone above mentioned. In the cervical bulb the region of the inner root bundle was degenerated, and most on the left side. In the medulla oblongata the degeneration extended to the boundary zone between the posterior column bundle and Goll's columns, decreasing in extent and intensity; the lateral columns and grey substance normal. In carmine preparations atrophy of nerve fibres, and increase 
of connective tissues were seen; no granular cells; a few corpora amylacea; anterior horn cells intact.

Dr. Schultze refers to several interesting points in this case. The small volume of the whole cord, which he thinks may be a congenital condition in cases of hereditary ataxy; the recovery from ataxic symptoms whilst the lesion of the lateral parts of the cuneati in almost the whole extent of the cord remained; the paræsthesia of the left ulnar region in connexion with the severe affection of the left cuneated columns in the cervical bulb; the moderate amount of degeneration of the posterior columns in the lumbar bulb, apparently leading to no sensory phenomena in the lower limbs; but the important feature was that the initial symptoms were all recovered from for years, except the bladder weakness and the absence of the patellar reflex. in spite of persistent grave anatomical lesions, and he asks : "Does this show that the anatomical lesion exists even in the earliest stages of tabes, when the symptoms are few, and that the view that a symptom stage precedes that of true anatomical destruction is untenable." At any rate a case like this suggests to us that no instance of so.called cure of tabes should be considered as such unless, death having resulted from some cause alien to the tabes itself, the posterior portions of the cord are found healthy. In a case in which the ataxic symptoms were peculiarly prominent, the patient not being able to guide his legs at all, even with the help of sight, and with the support of an arm on each side, under the long-continued use of ergot the gait became normal, and he left the hospital able to walk straight and in a perfectly coördinate manner with closed eyes. The patient went out thinking himself cured, and returned in about a year paraplegic, and after some months died. Apart from the extension of the lesion into more anterior reyions of the cord, the posterior root zones were found sclerosed in an extreme degree, and it was quite evident that during the remission of the symptoms the lesion of the cord had not improved at all.

In this case the duration of the disease was from seven to eight years, and the temporary improvement took place after four years' ailment, so that it does not directly bear upon the question of the curability of tabes in a pre-ataxic stage. But it is an instance of very complete remission of some of the gravest phenomena, with persistence of the lesion. There is no doubt that greater confidence would be felt in the curability of tabes if it were proved that this lesion is as closely connected with syphilis as some observers state. Erb considers that about 85 per cent. of such cases are specific, and Dr. Dowse, in a recent excellent paper, goes even farther when he says: "I feel sure that nearly every case of locomotor ataxy is due to syphilis, either hereditary or acquired; so much so, in fact, that it may well be called syphilitic ataxy." It is certain that a large proportion of cases of locomotor ataxy have had syphilis at some period of their life. It seems less certain that the syphilis has had much to do with the lesion, at least directly. Indirectly the subjects of previous syphilis may be more liable than others to any disorganising process ; but pathological evidence shows that syphilis affects the spinal centres with a different arrangement from that which obtains in tabes, and clinical experience proves that but few such cases derive much benefit from mercurials and iodide of potassium.

The old question therefore crops up again, "Can syphilis by its toxic influence on the nervous centre induce the various phenomena that are called the pre-ataxic signs of locomotor ataxy, without sclerosis of the posterior root zones?' If this can be proved, it seems only reasonable to believe that at this stage the mischief may be checked by treatment. But take the following case : A weakly man, of forty-four years of age, finds his walking powers, which had been very good, gradually diminish for some twelve months. He contracted syphilis in a severe form, and within ten days of the first appearance of the sore he suffered from decided paresis of the lower limbs. Within three weeks he became almost paraplegic as regards motion and sensation, with partial retention of urine. Patellar tendon-reflex absent ; diplopia from slight paralysis of the right external rectus. No retinal lesion pupils acted to light, though sluggishly. UInar numbness in each hand; sense of hearing confused. He was placed under antisyphilitic treatment, with the effect of making every symptom worse, and materially injuring the general health. Under a long course of phosphorus and strychnine with cod-liver oil the ulnar numbness diminished, sensation returned in the lower limbs; the power of walking was re- gained to a considerable extent, although a stick was necessary to enable the patient to walk quite straight. All the bladder symptoms vanished, and the diplopia was only observable at times in the day, when there had been much fatigue.

Is this recovery? No. The patellar tendon-reflex is still absent. Is the disease syphilitic? If so, why did not the appropriate treatment do good instead of harm, especially as in this case, if ever, the important symptoms would seem to have depended on syphilitic poisoning. Have we however, as yet, any proof that sclerosis can be recovered from? The remission of symptoms, even for several years, leads to the belief that under treatment directed to the tone of the vessels, or the nutrition of the cord, other tracts of this organ take on the duties that we consider the attributes of the posterior root zones. But during this very remission, if we may judge by pathological anatomy, the lesion is slowly, though surely, following a progressive course; and, although there is nothing imposaible in the more hopeful view of cure, I would still repeat that so far published factsare wanting to prove it, whilst, on the other hand, many cases of temporary improvement of symptoms have shown eventually post mortem a steady progress of the lesion.

Clifton.

ON THE

TREATMENT OF PSEUDO - MEMBRANOUS (DIPHTHERITIC) CONJUNCTIVITIS BY LOCAL APPLICATIONS OF SOLUTION OF SULPHATE OF QUININE.

\section{BY JOHN TWEEDY, F.R.C.S.,}

PROFESSOR OF OPHTHALMIC MEDICINE AND SURGERY IN UNIVERSITY COLLEGE, LONDON; ASSISTANT OPHTHALMIC SURGEON AT UNIVERSITY COLLEGE HOSPITAL; ASSISTANT SURGEON AT THE ROYAL LONDON OPHTHALMIC HOSPITAL, MOORFIELDS.

Two years ago I recorded several cases of true diphtheritic ophthalmia that had been successfully treated, so far as concerned the integrity of the cornea, by local applications of sulphate of quinine (THE LANCET, 1880, vol. i., pp. 125, 282). Since then I have similarly treated four other cases, and though the cornea remained wholly intact in only one of these, they all recovered with useful sight, and with, at worst, but slight nebulæ. To the quinine $\mathrm{F}$ ascribe the credit of saving the cornea in these cases from total destruction. Three of the four cases occurred in men and one in a woman. Two began as purulent conjunctivitis of gonorrhoal origin, and two were pseudo-membranous from the first. The former, a man and a woman, were admitted with advanced purulent conjunctivitis of the right eye, the left being free. In both instances, within a few days of admission, and while the inflammation of the right con. junctiva was subsiding, the left, in spite of protection by Buller's shield, became the seat of adherent pseudo-membranes. In neither did much pseudo-membrane appear on the right conjunctiva. As regards the two cases that were primarily pseudo-membranous, it is noteworthy that both occurred in men engaged in handling animal carcasses, one being a porter in Smithfield meat-market, the other a slaughterman in the country. No direct contagion from pharyngeal diphtheria or other similar disease could be traced in either of the cases. The meat-carrier thought be had acquired his disease from contact with an acrid "sweat" on some diseased American pork he had been carrying. The slaughterman did not connect his illness with his occupation, though he volunteered the statement that he had often killed diseased animals, and that but few calves have perfectly healthy livers, "not one in ten," most of them containing larger or smaller collections of putrid "matter."

I need not relate the details of the cases; they were alf treated in the wards of the Royal London Ophthalmic Hospital.

As soon as the nature of the disease was definitely recognised, all other treatment, if any, was stopped, and quinine lotion, containing four grains of sulphate of quinine, with a minimum of dilnte sulphuric acid to an ounce of water, was alone employed. As far as possible the diseased surfaces were kept constantly bathed with the 